\title{
Correction to: Long-term Outcome of Angioplasty Using a Wingspan Stent, Post-Stent Balloon Dilation and Aggressive Restenosis Management for Intracranial Arterial Stenosis
}

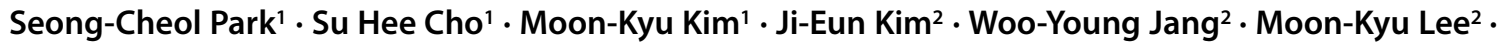 \\ Kwang-Deog Jo ${ }^{2}$ S Seung-Hoon You'
}

Published online: 7 February 2020

(c) Springer-Verlag GmbH Germany, part of Springer Nature 2020

\section{Correction to:}

\section{Clin Neuroradiol 2019}

https://doi.org/10.1007/s00062-019-00793-1

The original version of this article unfortunately contained some mistakes. The Institutional Review Board number was given wrongly in the Methods/Participants section and in the Compliance with ethical guidelines/Ethical standards section.

It must read GNHIRB2018-02-006 instead of 010-35959706.

The online version of the original article can be found under https://doi.org/10.1007/s00062-019-00793-1.

Seung-Hoon You

y77y85@hanmail.net

1 Department of Neurosurgery, Gangneung Asan Hospital, University of Ulsan College of Medicine, Bangdong-gil 38, 25440 Gangneung, Gangwon-do, Korea (Republic of)

2 Department of Neurology, Gangneung Asan Hospital, University of Ulsan College of Medicine, Gangneung, Korea (Republic of) 